\title{
The Fermilab Main Injector Dipole and Quadrupole Cooling Design and Bus Connections
}

\author{
J. A. Satti \\ Fermi National Accelerator Laboratory \\ P.O. Box 500, Batavia, Illinois 60510
}

June 1995

Presented at the 1995 Particle Accelerator Conference, Dallas, Texas, May 1-5, 1995. 


\section{Disclaimer}

This report was prepared as an account of work sponsored by an agency of the United States Government. Neither the United States Government nor any agency thereof, nor any of their employees, makes any warranty, express or implied, or assumes any legal liability or responsibility for the accuracy, completeness, or usefulness of any information, apparatus, product, or process disclosed, or represents that its use would not infringe privately owned rights. Reference herein to any specific commercial product, process, or service by trade name, trademark, manufacturer, or otherwise, does not necessarily constitute or imply its endorsement, recommendation, or favoring by the United States Government or any agency thereof. The views and opinions of authors expressed herein do not necessarily state or reflect those of the United States Government or any agency thereof. 


\title{
THE FERMILAB MAIN INJECTOR DIPOLE AND QUADRUPOLE COOLING DESIGN AND BUS CONNECTIONS
}

\author{
J. A. Satti \\ Fermi National Accelerator Laboratory* \\ P. O. Box 500, Batavia, IL 60510
}

\begin{abstract}
The proposed system for connecting the low conductivity water (LCW) and the electrical power to the magnets is explained. This system requires minimum maintenance. Stainless steel headers supply LCW to local, secondary manifolds which regulate the flow to the dipole and to the copper bus which conduct both power and cooling water to the quadrupole. A combination of ceramic feedthroughs and thermoplastic hoses insulate the piping electrically from the copper bus system. The utilities for the Main Injector are grouped together at the outside wall of the tunnel leaving most of the enclosure space for servicing. Space above the headers is available for future accelerator expansion. The new dipoles have bolted electrical connections with flexible copper jumpers. Separate compression fittings are used for the water connections. Each dipole magnet has two water circuits in parallel designed to minimize thermal stresses and the number of insulators. Two electrical insulators are used in series because this design has been shown to minimize electrolyses problems and copper ion deposits inside the insulators. The design value of the temperature gradient of the $\mathrm{LCW}$ is $8^{\circ} \mathrm{C}$.
\end{abstract}

\section{INTRODUCTION}

The Fermilab Main Injector (FMI) is a new $150 \mathrm{GeV}$ synchrotron now under construction at the Fermi National Accelerator Laboratory. ${ }^{1}$ The FMI will replace the existing Main Ring. New conventional dipole magnets, with water cooled conductors, will provide the primary bending for this accelerator. The proposed system for connecting the power and the water to the FMI is similar to the existing Main Ring. Where possible, the power bus is used to carry both power and water to the magnets.

\section{LOW CONDUCTIVITY WATER SYSTEM}

Figure 1 shows the FMI and the $8 \mathrm{GeV}$ Line LCW System. There will be six utility buildings uniformly spaced around the FMI ring. These are labeled MI-10, MI-20, MI-30, MI-40, MI-50, MI-60. Each utility building will supply power and cooling water to about 1,815 feet of circumference in the FMI. The closed loop system will receive makeup water from the Central Utility Building (CUB).

A total of 18 pumps will be installed around the ring

*Operated by the Universities Research Association, Inc., under contract with the U.S. Department of Energy with 3 pumps per service building. Each pump has a $100 \mathrm{hp}$ motor and delivers 550 GPM of LCW with a pressure head of 164 psi (380 TDH). Six inch stainless steel pipe headers will be installed above the magnets along the 10,891- foot circumference of the FMI. Eight inch headers will be used to connect the pumps from the service buildings to the manifolds in the accelerator enclosure.

All components arc connected in parallel and, with the proper hydraulic resistance across each secondary manifold, the local water distribution will be balanced between service buildings. The centrifugal pumps, also connected in parallel with the magnets, will share the flow and will balance the pressure head to match the resistance across the LCW manifolds. A similar LCW system has worked well in the existing Main Ring where the hydronics have been operational for twenty-three (23) years. ${ }^{2}$

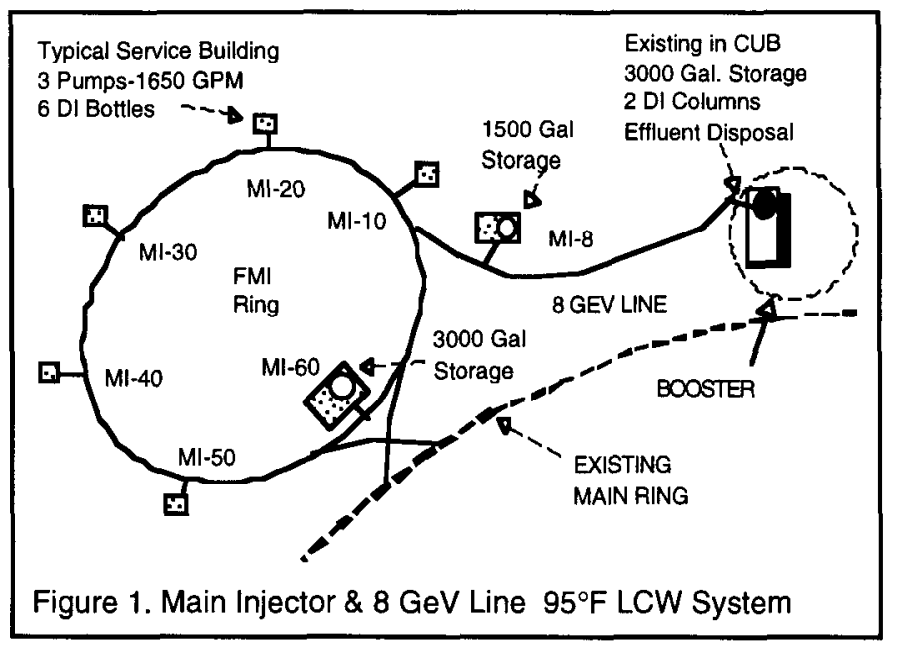

At the pipe penetrations leading to the enclosure, valves will be installed to isolate each sector of the ring. At each utility entrance, as well as at locations half-way in-between, the enclosure has a ceiling that is one foot higher than the standard tunnel. The purpose of this extra space is to provide space for the stainless steel expansion joints. At these locations, the enlarged enclosure allows the pipes to cross over the cable trays without obstructing the normal tunnel clearance for the magnet moving vehicle.

One heat exchanger per service building is required to transfer the LCW heat load to the pond water. The normal heat load removal capacity per building will be about 2.7 MW. Approximately 8,000 GPM of LCW will be required to cool the magnets, bus, and power supplies in the FMI enclosure and the service buildings. The centrifugal pumps are capable of delivering approximately $9,900 \mathrm{GPM}$ at the 
designed head of $164 \mathrm{psi}$. The temperature of the water is regulated to be $95^{\circ} \mathrm{F}$ by a 3 way control valve which diverts a portion of the water around the heat exchanger when less cooling is required. A constant flow of pond water is circulated in the tube side of the heat exchanger. The heat in the pond is removed hy evaporation. In the FMI design, the size of the ponds is the limiting factor in cooling the electrical components.

In each service building around the ring, portable, mixed-bed deionizer bottles will be installed. A continuous polishing flow of about 40 GPM per service building will be required to maintain low conductivity in the water. The bottles are only used for polishing action. Their use will guarantee that an average of $9 \mathrm{M} \Omega-\mathrm{cm}$ resistivity of the LCW will be maintained. LCW fills will be done from the CUB via the 8 $\mathrm{GeV}$ Line. The CUB has large industrial deionizer columns that meet the appropriate EPA guidelines for effluent discharge systems. The portable deionizer bottles will be regenerated in the CUB using its existing regeneration system. In service building MI-60, a 3,000 gallon combination storage and expansion tank is now being installed for emergency LCW make-up for the FMI. A 1,500 gallon tank will be in the MI-8 service building as additional storage. The FMI will require an estimated 37,000 gallons of LCW to fill the pipes, tanks, bus, and magnets. A net clockwise flow in the ring will be accomplished with restricting orifices at each of the entrances. In addition to the local water circulation around each service building, about $100 \mathrm{GPM}$ of circular flow will allow good mixing and deionizer processing at the CUB.

\section{ENCLOSURE UTILITIES}

The FMI components and associated utilities are grouped together at the outside wall of the tunnel leaving most of the space for servicing, as shown in figure 2. As with all accelerators, radiation damage to materials and exposure time to personnel is of great concern. Plans for servicing the accelerator must be taken into account so that maintenance time in any radiation environment is kept to a minimum. The general practice will be to replace a component rather than to repair it in place. All connections to the magnets are designed to be accessible from the inner space of the enclosure. Space above the headers is available for future accelerator expansion. The utilities are wall mounted with brackets bolted on channel inserts embedded in the enclosure wall at pre-determined regular intervals.

Figure 3 shows a schematic representation of the cooling for a typical hydraulic cell in the FMI. A group of magnets, consisting of two dipoles, one quadrupole, and a sextupole, is cooled in parallel from a 2 inch water manifold. This manifold can be isolated from the main 6 inch header water pressure with one 1-1/2 inch ball valve and two check valves to prevent back-flow. The secondary manifold permits access to the magnet connections and minimizes the number of requircd clcctrical insulators. The smaller manifolds are electrically insulated from ground. With a second insulator at the magnets, each LCW connection to the bus has two insulators in series. In the existing Main Ring, this design has reduced the copper ion deposits inside the insulators. One inch thermoplastic hose will be used for the insulators farthest away from the beam line. The flexibility of a hose is required where the thermal expansion of the main headers can be up to 3.5 inches after a shutdown. Ceramic insulators will be used at the magnets where radiation is more severe and where restrictions are required to regulate the water flow. Approximately two years ago thermoplastic hoses were installed in the Main Ring for testing the strength integrity in a radiation environment. So far, no signs of deterioration have heen detected for about fifty (50) operational hoses. The water pressure differential around the FMI ring is about 120 psi. The hydraulic cell is designed to give the correct flow to allow an average temperature rise of $8^{\circ} \mathrm{C}$ across each individual magnet.

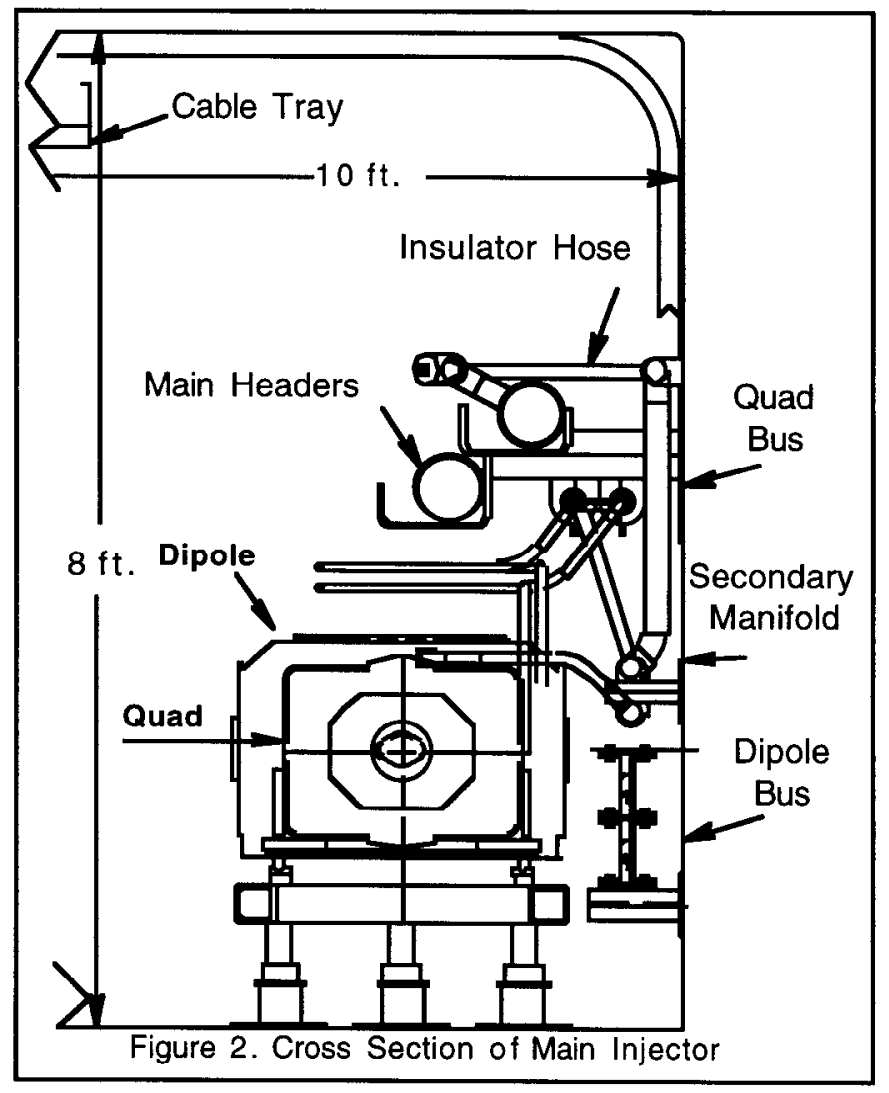

New, rectangular copper bus ( 1 "x4") will be used for connecting the dipoles in the enclosure around the quadrupoles. The bus will be supported from the wall with insulating structural fiberglass material. The support will have adjustments for alignment with the magnets. The flexible jumpers, with bolted connections allow for thermal expansion of the coils and the bus. Pipe bus ( 4 square inches in cross section) will be used at the entrances going to the power supplies in the service buildings. The quadrupoles will have a pipe bus ( 2 square inches in cross section ) with 2-1/8 inch outside diameter. This size will allow the use of standard water fittings for brazed connections. Porcelain clamps on channel supports will be used for all round bus. 


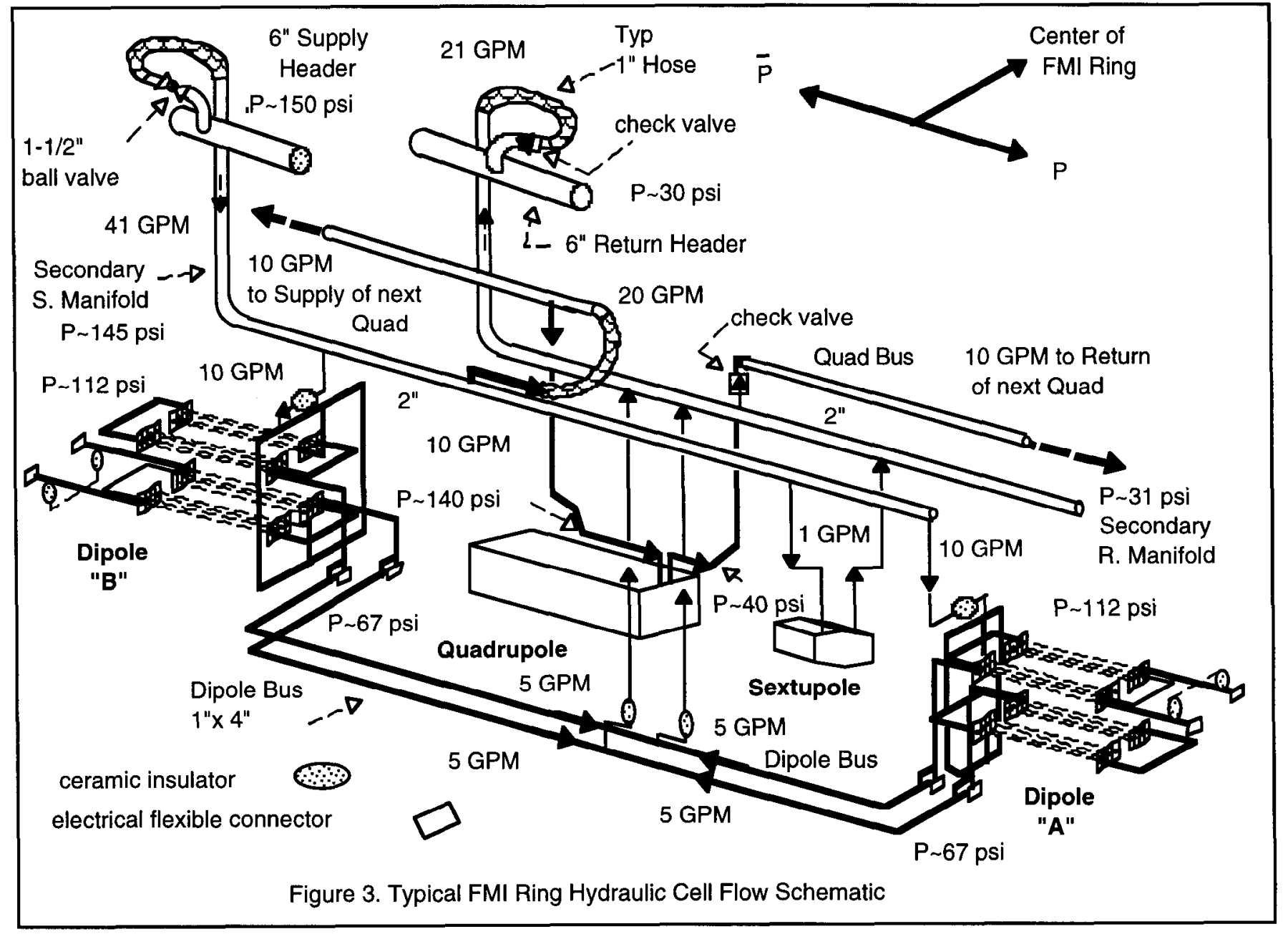

Figure 4 shows a prototype hydraulic cell installation in the normal enclosure next to the MI-60 area

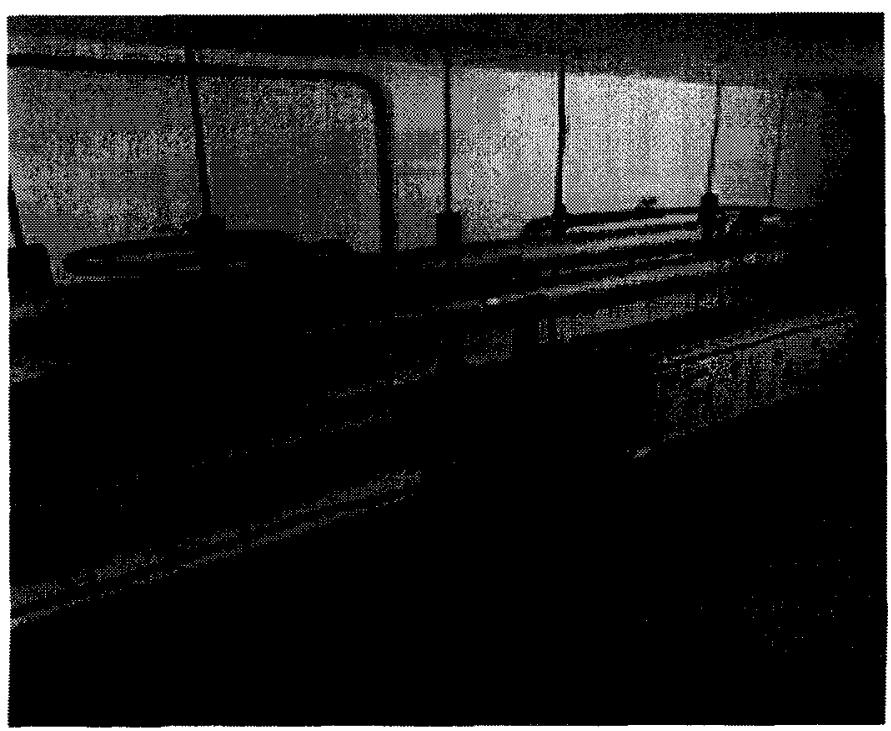

Figure 4. Prototype Q601 Hydraulic Cell Installation

\section{ACKNOWLEDGMENTS}

The design, procurement, and installation of the FMI Low Conductivity Water cooling and bus systems is the result of work of many people at Fermilab. I wish to acknowledge the contribution of M. Ball, J. Domanus, J. Fritz, P. Gentry, R. Gloor, T. Hamerla, B. Hoffman, R. Kellett, B. Krueger, T. Kuhar, C. Lee, J. Meisner, J. O'Malley, F. Rios, B. Rush and R. Schultz for the engineering, design and the technical assistance of the piping system. T. Larson contributed in the procurement of the components. I wish to thank R. Slazyk and $\mathrm{K}$. Williams for the installation coordination. The author would like to acknowledge the helpful suggestions of P. Martin, FMI Deputy Head for Accelerator Systems.

\section{REFERENCES}

[1] The Fermilab Main Injector Technical Design Handbook, August 1994.

[2] J. A. Satti, " The Power and Cooling Interconnection of The $200 \mathrm{GeV}$ Synchrotron Magnets", IEEE Trans. Nucl. Sci. , Vol. NS-16, p. 782, March 1969 